\section{Investigation on the Effect of Two Fat Metabolism Related Pathways on Intramuscular Fat Content in Pigs}

\author{
Chaogang Yao, Daxin Pang, Chao Lu, Aishi Xu, Peixuan Huang, \\ Hongsheng Ouyang* and Hao Yu* \\ Jilin Provincial Key Laboratory of Animal Embryo Engineering, College of Animal \\ Sciences, Jilin University, Changchun, Jilin Province 130062, People's Republic of \\ China
}

Chaogang Yao and Daxin Pang contributed equally to this work.

\begin{tabular}{l} 
Article Information \\
Received 07 April 2019 \\
Revised 30 July 2019 \\
Accepted 26 September 2019 \\
Available online 21 May 2021 \\
Authors' Contribution \\
\hline CY and DP performed the \\
experiments, analyzed the data of the \\
study and wrote the paper. CL, AX \\
and PH collected the samples. HO \\
and HY conceived and designed the \\
experiments. \\
Key words \\
Pig, Intramuscular fat, Gene \\
expression, PPAR signaling pathway, \\
qRT-PCR array
\end{tabular}

Article Information

Received 07 April 2019

Authors' Contribution

experiments, analyzed the data of the

study and wrote the paper. $C L, A X$

and $\mathrm{PH}$ collected the samples. HO

and $\mathrm{HY}$ conceived and designed the

experiments.

MF contentin the longissimus dorsi (LD involved in the PPAR and fatty acid metabolism signaling pathways were detected in the LD muscle of two pig breeds with different IMF contents (Large White and Min) by a quantitative real-time reversetranscription polymerase chain reaction (qRT-PCR) array. Our results showed that three lipid metabolismrelated biological processes lipogenesis, fatty acid transport and fatty acid oxidation in these two pathways showed significant differences in activation between Large White and Min pigs. The activation of the PPAR and fatty acid metabolism signaling pathways may play a positive role in reducing IMF content in pigs.

\section{INTRODUCTION}

$\mathrm{P}$ ork is a major meat source for humans in modern society (Puig-Oliveras et al., 2014). Intramuscular fat (IMF), also known as marbling, is an important determinant of pork quality. IMF content is positively correlated with several pork quality traits such as tenderness, juiciness, and flavor (Li et al., 2018). Moreover, many studies have indicated that pork quality is significantly improved when the IMF content obviously increases (Hamill et al., 2013; Madeira et al., 2013). In fact, pork with a suitable IMF content is favored by consumers (Font-i-Furnols et al., 2012; Wang et al., 2017). Therefore, we should aim to improve the IMF content of pork in the modern pig industry. It is well known that IMF content varies among different pig breeds (Dai et al., 2009; Gao et al., 2011; Casellas et al., 2013; Wu et al., 2013; Cui et al., 2016; Li et al., 2016; Lim et al., 2017). For example, the Large White pig, which is a famous commercial lean pig breed worldwide, has very low IMF content in their skeletal muscles. In contrast, the Chinese

\footnotetext{
Corresponding author: ouyh@jlu.edu.cn; yu_hao@ jlu.edu.cn 0030-9923/2021/0004-1353 \$ 9.00/0

Copyright 2021 Zoological Society of Pakistan
}

indigenous pig breeds have higher IMF content and superior quality pork. The Min pig is an excellent indigenous breed raised in the northeastern China (Gao et al., 2011) Min pigs breed prolifically and have strong tolerance to extreme environment, such as diseases, cold, crude and poor-quality feed. They also have high IMF content and better meat quality. Compared with Large White, the Min pig has a lower growth rate and lean meat ratio. Thus, these two pig breeds are ideal models for investigating the molecular mechanisms responsible for differences in fat deposition between Chinese indigenous pigs and famous commercial lean pigs.

To the best of our knowledge, the IMF content of pigs depends on the balance between lipogenesis and lipolysis, which includes fatty acid uptake, fat mobilization, fatty acid transport and fatty acid oxidation (Zhao et al., 2009; Zhang et al., 2015). As a complex porcine trait, IMF content may be affected by multiple genes and metabolic processes. Over the past decades, many studies are focus on the relationship between IMF content and single or multiple candidate genes. In several studies, the expression levels of PPARA, LPL, ACSL1, SCD and $P P A R \gamma$ genes are correlated with IMF content (Yang et al., 2012; Wang et al., 2013, 2016). In fact, these genes are involved in the peroxisome proliferator-activated receptor 
(PPAR) (ssc03320) or fatty acid metabolism ( $\operatorname{ssc} 01212)$ pathways, which are two well-known signaling pathways affecting lipid metabolism (KEGG Pathway Database). The activation of these two signaling pathways is critical to IMF deposition in pigs. However, fewer studies have focused on identifying essential genes related to porcine fat deposition at the whole-pathway level. Fortunately, with the release of porcine genome, we can identify all the genes in one pathway at once, enabling us to study IMF content trait based on whole signaling pathways rather than single genes. Therefore, although there are many factors that could participate in regulating the development of IMF, the transcriptional levels of related genes in these two pathways may partly illustrate the difference in IMF content between these two diverse pig breeds. Consequently, the objective of this study was to detect the expression of all genes involved in the PPAR and fatty acid metabolism signaling pathways in two pig breeds with different IMF contents.

Over the last decade, microarray and next-generation sequencing (NGS) technologies have been widely used in transcriptomic studies of different porcine tissues. For many researchers, the quantitative real-time reversetranscription polymerase chain reaction (qRT-PCR) has been widely considered the gold standard for measuring gene expression of a small group of selected genes due to its rapidity, simplicity and low cost (Morales-Prieto et al., 2017). In addition, the qRT-PCR array has been used in many studies and is an ideal and reliable tool for analyzing the expression levels of pathway-related genes (Tao et al., 2012; Morales-Prieto et al., 2017). Thus, in this study, all genes of the PPAR and fatty acid metabolism signaling pathways were detected in Min and Large White pig breeds by a qRT-PCR array. Our results may provide valuable information for elucidating the molecular mechanisms of different IMF contents in pigs.

\section{MATERIALS AND METHODS}

\section{Ethics statement}

All experiments were performed according to the guidelines of the University Committee on the Use and Care of Animals at Jilin University (approval ID: 201706030).

\section{Animals and sample collection}

The experimental pigs were raised under standard conditions at the Institute of Animal Husbandry Research, Heilongjiang Academy of Agricultural Sciences (Harbin, China). Two different breeds: Large White $(n=3)$ and Min $(n=3)$ pigs at an average age of 180 days were chosen randomly and slaughtered in a local abattoir. Samples of longissimus dorsi (LD) muscle between the 10th and 12th ribs were collected and divided into two parts, one part was quickly frozen in liquid nitrogen, and stored at $-80^{\circ} \mathrm{C}$ until they were used in the qRT-PCR array, and another part was stored in $4{ }^{\circ} \mathrm{C}$ for determination of the IMF content.

\section{Determination of IMF content}

For LD muscles of Large White and Min pigs, the IMF content was determined as crude fat using the Soxhlet extraction method with petroleum ether (Supakankul and Mekchay, 2016) and each sample was repeated three times. In details, the LD samples were dried in an oven at $65{ }^{\circ} \mathrm{C}$ until constant weight; and the dried LD samples were cooled to room temperature and ground into powder. About $1 \mathrm{~g}$ dried LD samples weighed was dried in an oven at $105{ }^{\circ} \mathrm{C}$ and then put into a fat package. This sample was extracted with petroleum ether for 6-7 hours, and then refluxed the petroleum ether. The statistical formula used for the determination of IMF content was as follows: IMF content $=(\mathrm{W} 3-\mathrm{W} 1) /(\mathrm{W} 2-\mathrm{W} 1) * 100 \%$, where $\mathrm{W} 3$-the weight of fat package + sample after extraction and drying, W1 - the weight of fat package, W2- the weight of fat package + sample after drying.

\section{$R N A$ extraction and $q R T-P C R$ array}

A total of six LD samples were used to perform the qRT-PCR array. Total RNA from the LD samples was extracted using TRIzol- $\mathrm{A}^{+}$Reagent (TIANGEN, Beijing, China), and first-strand cDNA was then synthesized using a BioRT cDNA First Strand Synthesis Kit (Bioer Technology, Hangzhou, China) following the manufacturer's instructions. The primers of genes in the selected pathways (KEGG Pathway Database) are listed in Supplementary Table I. The qRT-PCR array was performed with a Bio Easy SYBR Green I Real Time PCR kit (Bioer Technology) on an $\mathrm{iQ}^{\mathrm{TM}} 5$ real-time PCR detection system (Bio-Rad) according to the manufacturer's instructions (Qiagen).

\section{Bioinformatics and statistical analysis}

In this study, the LD muscles of Large White pigs were used as experimental group, the LD muscles of Min pigs were used as control group. Different statistical tools were used for analyzing the data. Graph Pad Prism 6.01 (Graph Pad Software, San Diego, CA, USA) was used for analyzing our results. Student's t-tests were used to compare the control and experimental groups. For all comparisons, ${ }^{*} \mathrm{p}<0.05,{ }^{* *} \mathrm{p}<0.01, * * * \mathrm{p}<0.001,{ }^{* * * *} \mathrm{p}$ $<0.0001$, were considered significant difference. An MS-Excel sheet (Supplementary Table II) with macros downloaded from the manufacturer's website (http://www. 
sabiosciences.com/pcrarraydataanalysis.php) was used to analyze the qRT-PCR array data based on a protocol (http:// pcrdataanalysis.sabiosciences.com/pcr/arrayanalysis.php) provided by SABiosciences (Qiagen). The $2^{-\Delta \mathrm{CT}}$ method was used to calculated the $\mathrm{Ct}$ values from the qRT-PCR array data. Five genes (B2M, GAPDH, HPRT1, ACTB and $R P L 13 A)$ were used as reference genes. A p value less than 0.05 and $\left|\log _{\text {Fold Change(FC) }}\right| \geq 1$ were regarded as the cutoff thresholds for differentially expressed genes(DEGs). TB tools (https://github.com/CJ-Chen/TBtools) was used to construct the heat map of the qRT-PCR array and the Venn diagrams of differentially expressed genes (DEGs). The STRING database was used to predict protein interactions and construct the network for DEGs (Szklarczyk et al., 2015). The protein-protein interaction (PPI) network was visualized by Cytoscape (Shannon et al., 2003).

\section{RESULTS}

IMF content of LD muscles in the large white and min pigs

The IMF content assay indicated that the IMF content of Large White LD muscles was significantly lower than that of Min pig LD muscles (1.693\% and $4.963 \%$, respectively, $\mathrm{P}<0.0001$ ) (Fig. 1). These results indicated that these two pig breeds were fit for identifying the expression of genes in these two signaling pathways associated with different IMF content.

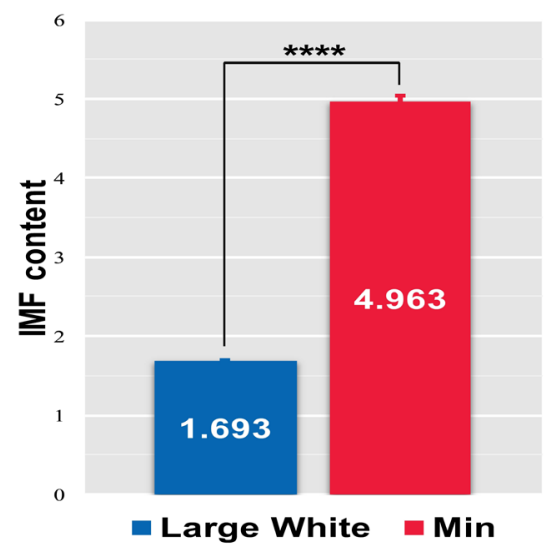

Fig. 1. Detection of IMF content in LD muscles of Large White and Min pigs. Data represent means $\pm \operatorname{SEM}(n=3)$, $* * * * P<0.0001$.

Identification of the PPAR signaling pathway in the LD muscles of the two pig breeds

The PPAR signaling pathway (ssc03320) consists of 69 genes (KEGG Pathway Database). In this study, these genes had their expression detected by the qRTPCR array. The gene expression profile is significantly different between Large White and Min group, set of genes can be successfully clustered (Fig. 2A). A colored map shows a graphical representation of DEGs in Large White group against Min group, red and green color represent upregulated and downregulated genes respectively (Fig. 2B). Our results showed that 42 out of the 69 examined genes were differentially expressed between the Large White and Min group, with 20 being upregulated and 22 being downregulated in the LD muscle of Large White pigs (Table I). Among the 42 DEGs, some genes related to fatty acid transport (FAT/CD36, FABP1, ACSL1, LPL, and $A C S B G 2)$, fatty acid oxidation (CPT1A, CPT1B, $A C A A 1, A C A D M$ and $A C A D L$ ), and fatty acid biosynthesis ( $S C D$ and $S C D 5$ ). In addition, we used STRING database and Cytoscape software to construct the PPI network for 42 DEGs. The PPI network contained 40 nodes and 245 edges, the most significant 10 node degree genes (PPARA, PPARG, ACSL1, CPT1A, CPT1B, FABP1, $C D 36, L P L, S C D$, and $F A B P 4)$ were selected as hub genes (Fig. 3 and Table II). Moreover, taken into account the results of colored map and PPI network, 12 genes in the PPAR signaling pathway (PPARA, CD36, FABP1, LPL, ACSL1, CPT1A, CPT1B, ACAA1, ACADL, ACADM, $P P A R G$ and $S C D$ ) were selected as key hub genes, and their expression patterns are presented in Figure 4, these genes are associated with fatty acid transport, fatty acid oxidation, fatty acid biosynthesis and IMF deposition. Taken together, these results show that the PPAR signaling pathway is more active in the Large White breed than in the Min breed.

GO BP enrichment of DEGs in the PPAR signaling pathway

As shown in Figure 5, the BPs participated by upregulated genes were mainly involved in fatty acid $\beta$-oxidation, fatty acid oxidation, lipid oxidation, fatty acid transport and fatty acid catabolic processes. These results indicated that compared with the LD muscle of Min pigs, the LD muscle of Large White pigs consumes more fat during energy metabolism, and this may explain the lower fat deposition in Large White pigs.

Identification of the fatty acid metabolism signaling pathway in the LD muscles of the two pig breeds

The fatty acid metabolism signaling pathway (ssc01212) consists of 47 genes (KEGG Pathway Database). In this study, these genes had their expression detected by the qRT-PCR array. For heatmap, the genes showed significant expression patterns between Large White and Min group, and they successfully clustered into several sets (Fig. 6A). For colored map (Fig. 6B), 

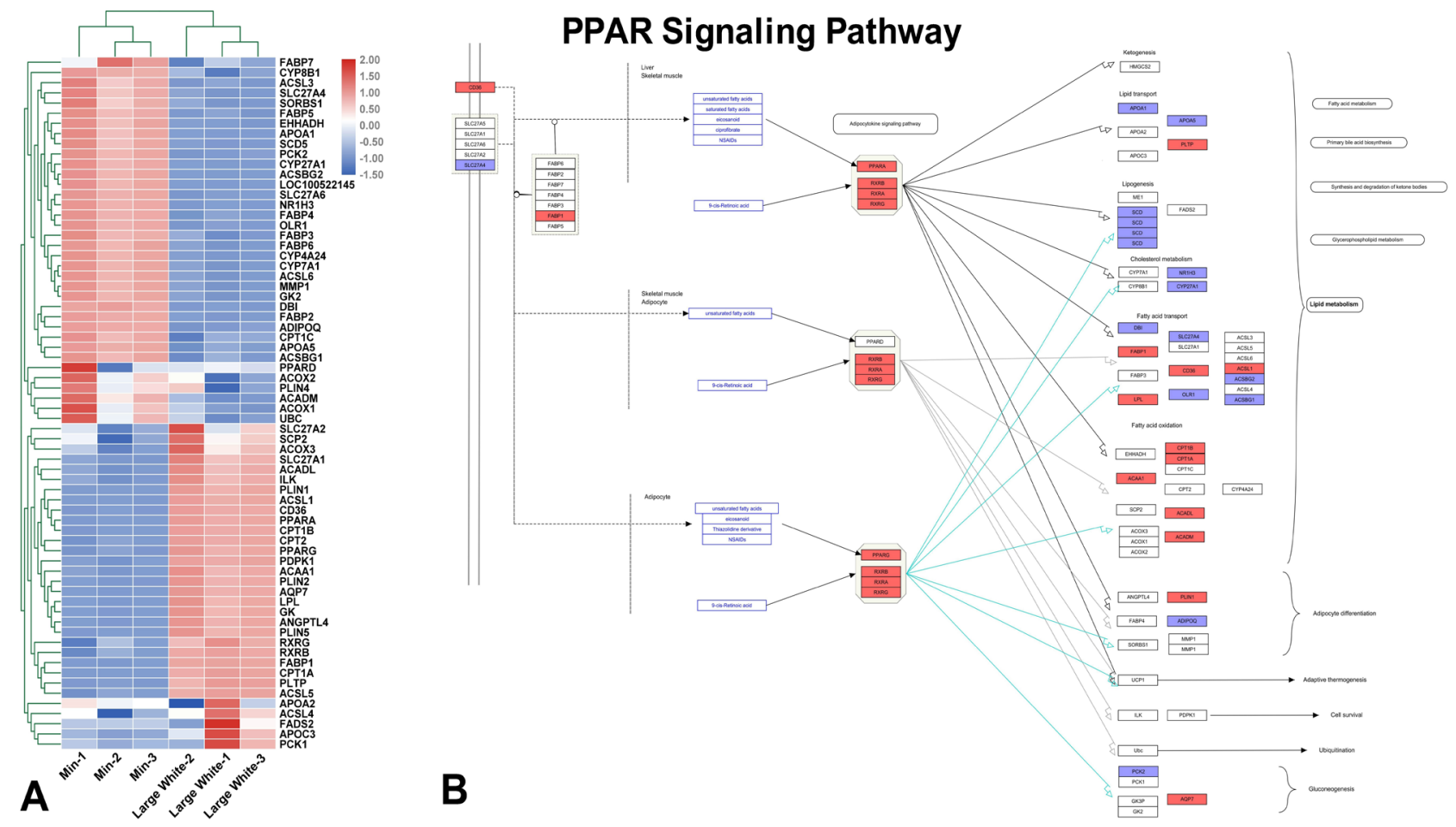

Fig. 2. qRT-PCR array results for the PPAR signaling pathway in two pig breeds. (A) A heatmap of all qRT-PCR array genes in the PPAR signaling pathway. The colors (blue, black, and red) represent the gene expression level in the LD of two pig breeds (Min and Large White). (B) Colored map of the PPAR signaling pathway. Upregulated and downregulated genes are colored in red and blue, respectively.

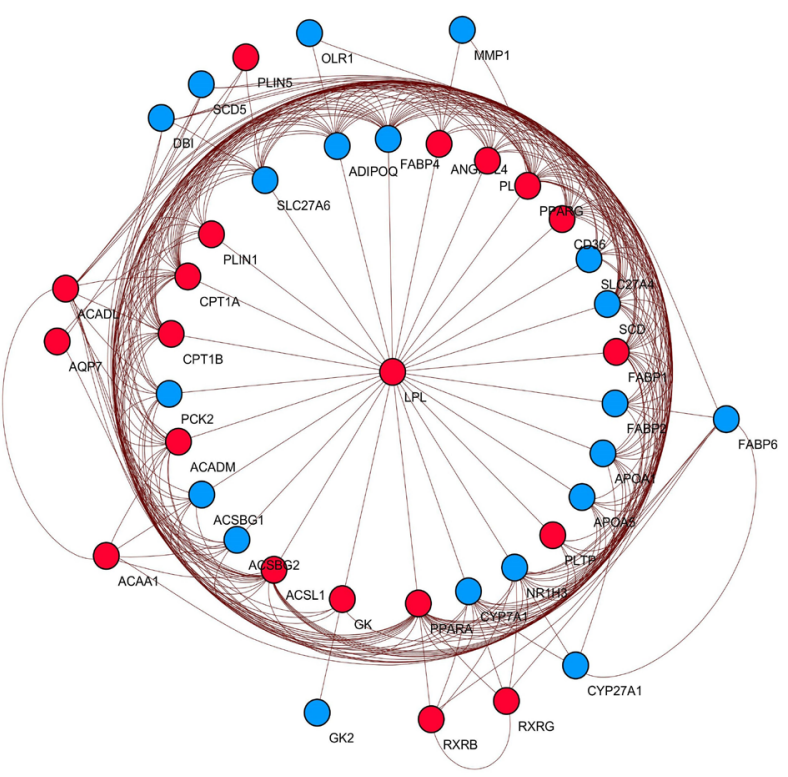

Fig. 3. PPI network for the DEGs in the PPAR signaling pathway. Upregulated and downregulated genes are colored in red and blue, respectively. Node stands for the protein (gene); edge stands for the interaction of proteins(genes).

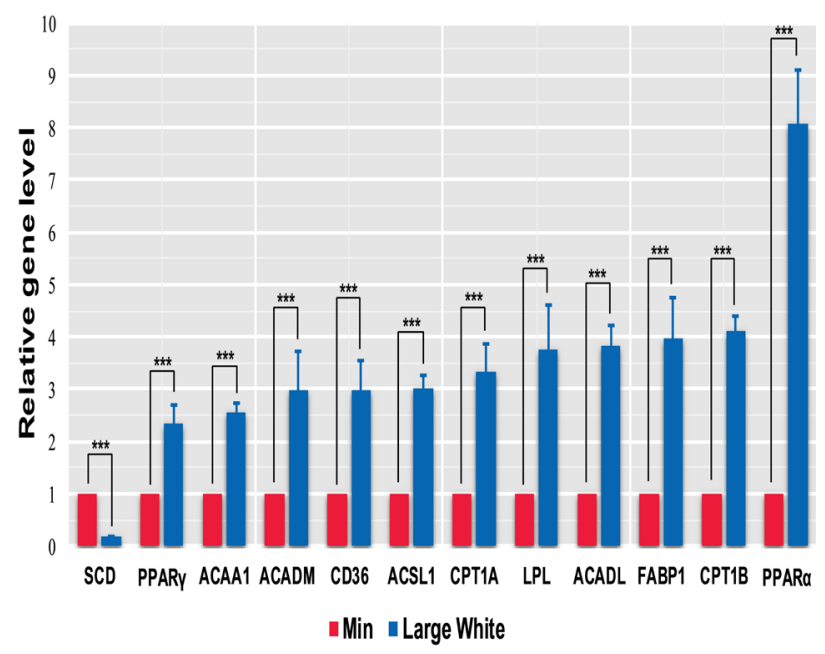

Fig. 4. Comparisons of the expression levels of twelve key hub genes (PPARA, CD36, FABP1, LPL, ACSL1, CPT1A, $C P T 1 B, A C A A 1, A C A D L, A C A D M, P P A R G$ and $S C D)$ in the PPAR signaling pathway in the two pig breeds. A p value less than 0.05 and $\left|\log _{\text {Fold Change(FC) }}\right| \geq 1$ were regarded as the cutoff thresholds for DEGs. All data are shown as means $\pm \operatorname{SEM}(\mathrm{n}=3),{ }^{*} * P<0.001$. 

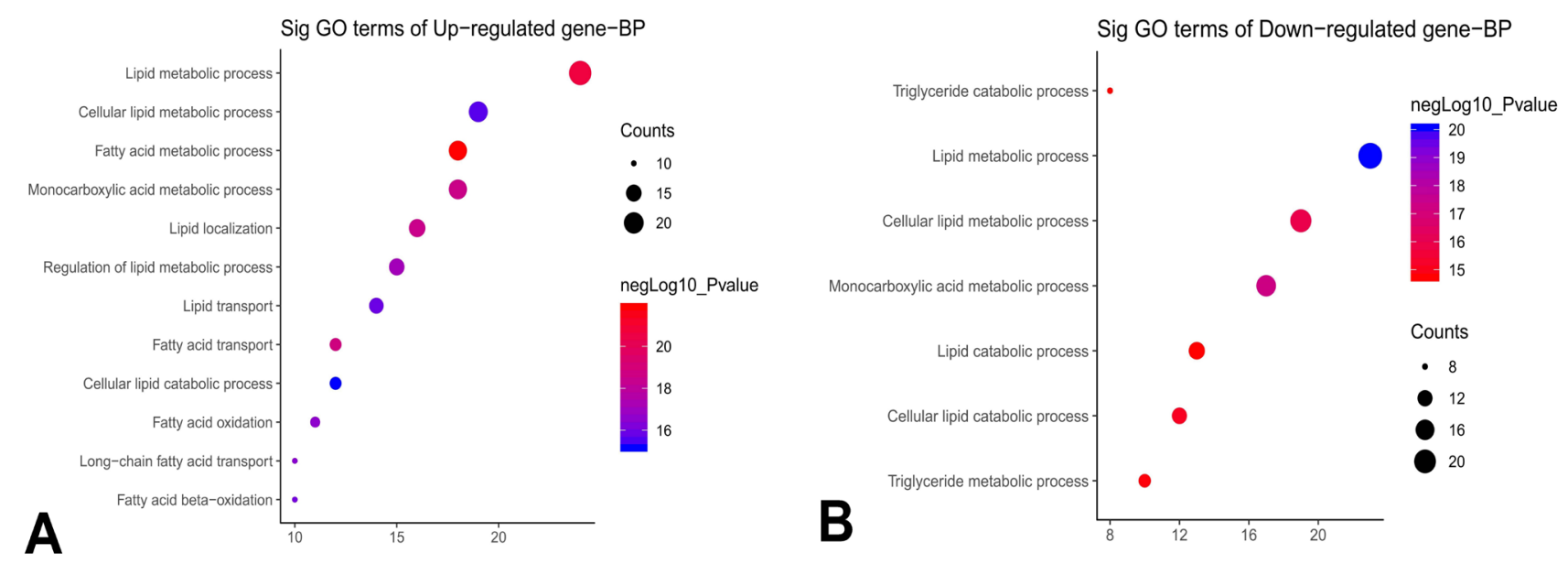

Fig. 5. GO Biological Process (BP) enrichment of upregulated (A) and downregulated (B) genes in the PPAR signaling pathway.
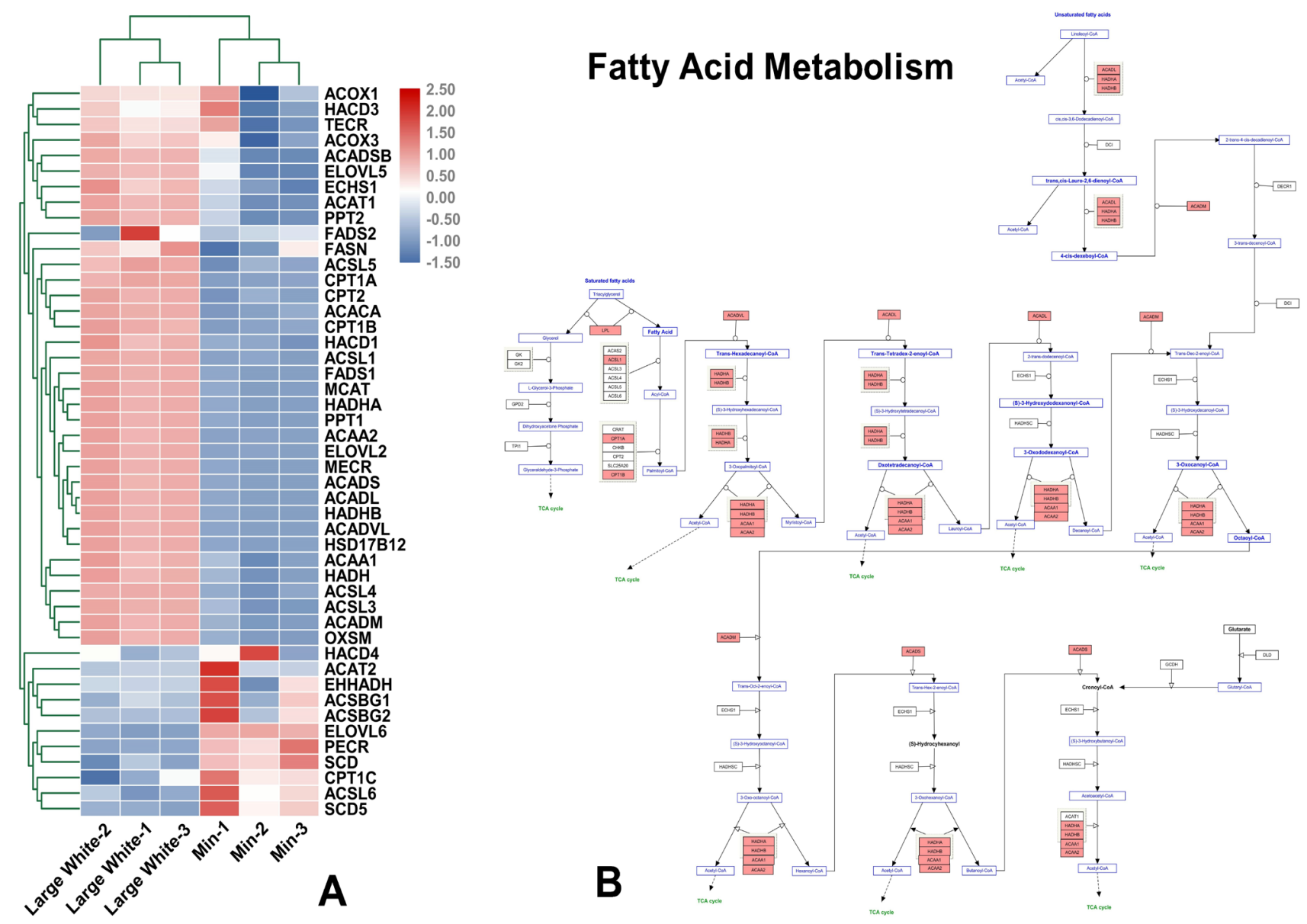

Fig. 6. qRT-PCR array results for the fatty acid metabolism signaling pathway in two pig breeds. (A) A heatmap of all qRT-PCR array genes in the fatty acid metabolism signaling pathway. The colors (blue, black, and red) represent gene expression levels in the LD of two pig breeds (Min, and Large White); (B) Colored map of the fatty acid metabolism signaling pathway. Upregulated and downregulated genes are colored in red and blue, respectively. 
Table I. qRT-PCR array results for the PPAR signaling pathway (Large White-Min).

\begin{tabular}{|c|c|c|c|}
\hline Gene symbol & Fold-change & P-value & Regulation \\
\hline PPARA & 8.084412043 & $9.72 \mathrm{E}-06$ & $\mathrm{Up}$ \\
\hline PLIN5 & 6.840235862 & 8.62E-09 & Up \\
\hline ANGPTL4 & 5.217036652 & $1.14 \mathrm{E}-11$ & Up \\
\hline$G K$ & 5.00157363 & $7.51 \mathrm{E}-12$ & Up \\
\hline$R X R B$ & 4.921137382 & $1.99 \mathrm{E}-02$ & Up \\
\hline$R X R G$ & 4.131238515 & $1.61 \mathrm{E}-03$ & Up \\
\hline$C P T 1 B$ & 4.096161077 & 2.79E-06 & Up \\
\hline$F A B P 1$ & 3.961630498 & $3.89 \mathrm{E}-10$ & Up \\
\hline$A Q P 7$ & 3.919214964 & $9.43 \mathrm{E}-11$ & Up \\
\hline$A C A D L$ & 3.843627184 & $6.38 \mathrm{E}-09$ & Up \\
\hline$L P L$ & 3.748782175 & 7.94E-08 & Up \\
\hline PLIN1 & 3.542042156 & $1.87 \mathrm{E}-07$ & Up \\
\hline CPT1A & 3.348062077 & $5.37 \mathrm{E}-10$ & Up \\
\hline PLIN2 & 3.188133697 & $2.38 \mathrm{E}-10$ & Up \\
\hline ACSL1 & 3.007946783 & 5.34E-09 & Up \\
\hline$C D 36$ & 2.988137088 & $5.04 \mathrm{E}-10$ & Up \\
\hline$A C A D M$ & 2.967591733 & $2.26 \mathrm{E}-06$ & Up \\
\hline$A C A A 1$ & 2.56635317 & $1.60 \mathrm{E}-13$ & Up \\
\hline PPARG & 2.348890709 & 4.72E-06 & Up \\
\hline PLTP & 2.02949545 & $7.26 \mathrm{E}-10$ & Up \\
\hline$D B I$ & -2.05013384 & 2.67E-08 & Down \\
\hline CYP $4 A 24$ & -2.12501151 & $2.04 \mathrm{E}-13$ & Down \\
\hline APOA1 & -2.14154421 & $1.20 \mathrm{E}-09$ & Down \\
\hline$M M P 1$ & -2.1442043 & $1.10 \mathrm{E}-11$ & Down \\
\hline CYP7A1 & -2.1442043 & $6.87 \mathrm{E}-14$ & Down \\
\hline$G K 2$ & -2.1442043 & $1.47 \mathrm{E}-13$ & Down \\
\hline SLC27A4 & -2.14516778 & $3.75 \mathrm{E}-09$ & Down \\
\hline FABP6 & -2.15185161 & 8.05E-09 & Down \\
\hline FABP4 & -2.16469078 & 7.06E-09 & Down \\
\hline CYP27A1 & -2.16783714 & $9.70 \mathrm{E}-12$ & Down \\
\hline$S C D$ & -2.17054507 & $1.23 \mathrm{E}-04$ & Down \\
\hline$A C S B G 1$ & -2.23209128 & $7.14 \mathrm{E}-02$ & Down \\
\hline OLR1 & -2.64415442 & $1.18 \mathrm{E}-08$ & Down \\
\hline$A C S B G 2$ & -2.78828039 & 7.69E-04 & Down \\
\hline$A D I P O Q$ & -2.79931981 & $5.91 \mathrm{E}-05$ & Down \\
\hline SCD5 & -2.9605646 & $6.16 \mathrm{E}-06$ & Down \\
\hline$F A B P 2$ & -3.12676057 & $1.73 \mathrm{E}-11$ & Down \\
\hline NR1H3 & -3.37368493 & $1.17 \mathrm{E}-09$ & Down \\
\hline$P C K 2$ & -3.76994247 & $2.40 \mathrm{E}-07$ & Down \\
\hline$S L C 27 A 6$ & -4.03289334 & 4.30E-07 & Down \\
\hline LOC100522145 & -4.63203509 & $5.65 \mathrm{E}-12$ & Down \\
\hline APOA5 & -5.63906119 & $1.58 \mathrm{E}-03$ & Down \\
\hline
\end{tabular}

Table II. The summary for the PPI network of DEGs in the PPAR signaling pathway.

\begin{tabular}{|c|c|}
\hline Gene symbol & Degree \\
\hline$L P L$ & 26 \\
\hline PPARA & 25 \\
\hline PPARG & 25 \\
\hline CPT1A & 23 \\
\hline$S C D$ & 22 \\
\hline ACSL1 & 22 \\
\hline$F A B P 1$ & 22 \\
\hline FABP4 & 22 \\
\hline СРT1B & 19 \\
\hline CD36 & 18 \\
\hline$A C A D M$ & 17 \\
\hline NRIH3 & 17 \\
\hline ADIPOQ & 17 \\
\hline SLC27A6 & 16 \\
\hline PLIN2 & 15 \\
\hline CYP7A1 & 15 \\
\hline APOA1 & 14 \\
\hline PCK2 & 13 \\
\hline$A C A D L$ & 13 \\
\hline SLC27A4 & 11 \\
\hline PLIN1 & 11 \\
\hline$F A B P 2$ & 10 \\
\hline$A C S B G 1$ & 9 \\
\hline$A C S B G 2$ & 9 \\
\hline APOA5 & 9 \\
\hline ANGPTL4 & 9 \\
\hline FABP6 & 7 \\
\hline$D B I$ & 6 \\
\hline$G K$ & 6 \\
\hline PLTP & 6 \\
\hline$A C A A 1$ & 6 \\
\hline SCD5 & 5 \\
\hline$R X R G$ & 5 \\
\hline$R X R B$ & 5 \\
\hline CYP27A1 & 4 \\
\hline PLIN5 & 3 \\
\hline$A Q P 7$ & 3 \\
\hline$M M P 1$ & 2 \\
\hline OLRI & 2 \\
\hline$G K 2$ & 1 \\
\hline
\end{tabular}


upregulated and downregulated genes in the Large White group were in tuitively presented by colored in red and blue, respectively. The results showed compared with Min group, there are 18 genes upregulated and 13 genes downregulated in Large White group (Table III), these including several genes related to fatty acid oxidation (ACAA2, ACADS, ACADM, ACADL, ACADVL, CPT1A, $C P T 1 B, H A D H A$, and $H A D H B)$, fatty acid transport ( $A C S B G 2$ and $A C S L 1)$ and fatty acid biosynthesis (SCD and SCD5). Moreover, PPI networks of 31 DEGs were established by using STRING database and Cytoscape software, which included 31 nodes and 178 edges (Fig. 7 and Table IV). In the PPI networks, the most significant 13 node degree genes (ACAA2, ACACA, ACADL, ACADM, $A C A D S, A C S B G 2, A C S L 1, C P T 1 A, C P T 1 B, E H H A D H$, $H A D H A, H A D H B$, and HSD17B12) were defined as hub genes. Moreover, taken into account the results of colored map and PPI network, 13 genes, 6 genes only in the fatty acid metabolism signaling pathway ( $A C A C A, A C A A 2$, $A C A D S, A C A D V L, H A D H A$ and $H A D H B)$ and 7 genes (ACAA1, CPT1A, CPT1B, ACADL, ACADM, ACSL1 and $S C D$ ) shared by the PPAR and fatty acid metabolism signaling pathways, were selected as key hub genes, and their expression patterns are presented in Figures 8 and 4, respectively. These 13 genes are also involved in fatty acid transport, fatty acid oxidation, fatty acid biosynthesis and IMF deposition. After analyzing these results, we could see that the fatty acid metabolism signaling pathway is more active in the Large White breed than in the Min breed.

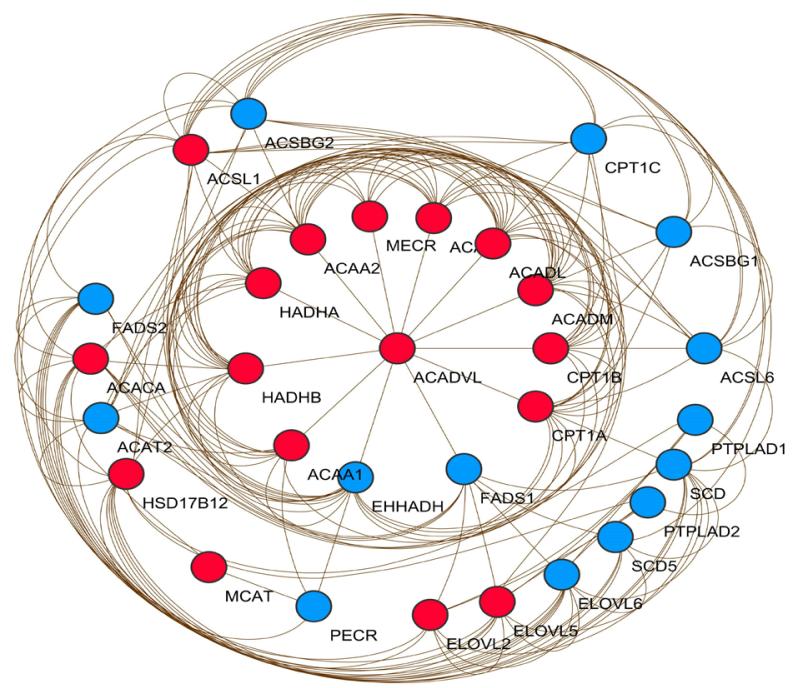

Fig. 7.PPInetwork for the DEGs in the fatty acid metabolism signaling pathway. Upregulated and downregulated genes are colored in red and blue, respectively. Node stands for the protein (gene); edge stands for the interaction of proteins(genes).

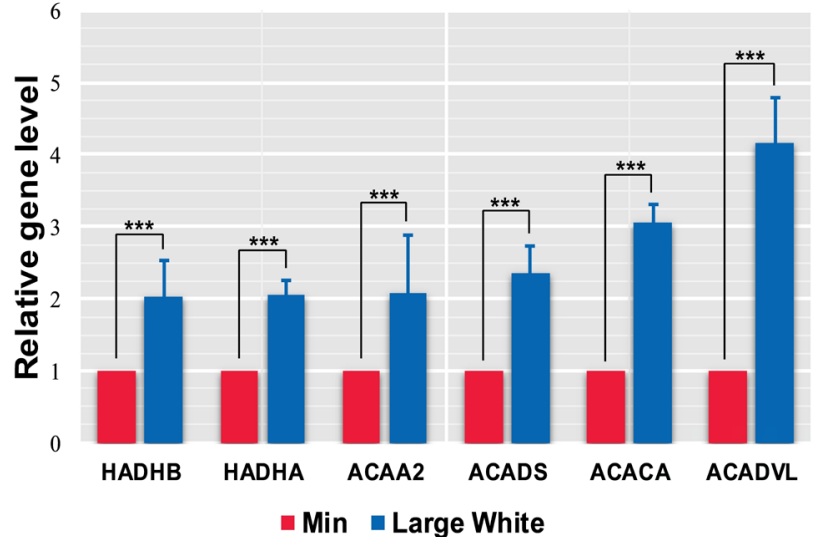

Fig. 8. Comparisons of the expression levels of six key hub genes (ACACA, ACAA2, ACADS, ACADVL, HADHA and $H A D H B)$ in the fatty acid metabolism signaling pathway in the two pig breeds. A p value less than 0.05 and $\left|\log _{\text {Fold Change( } \mathrm{FC})}\right| \geq 1$ were regarded as the cutoff thresholds for DEGs. All data are shown as means \pm SEM $(n=3)$, $* * * P<0.001$.

GO BP enrichment of DEGs in the fatty acid metabolism signaling pathway

As shown in Figure 9, the BPs participated by upregulated genes were mainly involved in fatty acid $\beta$-oxidation, fatty acid oxidation, lipid oxidation and fatty acid catabolic processes. These results indicated that the upregulated genes of the fatty acid metabolism signaling pathway mainly participated in reducing the fat deposition in the LD muscle of Large White pigs.

\section{The DEGs shared by the PPAR and fatty acid metabolism signaling pathways}

The PPAR and fatty acid metabolism signaling pathways shared 20 genes (Fig. 10, Table V). Of these 20 shared genes, 10 were differentially expressed in the LD muscle of Large White pigs, with 6 being upregulated and 4 being downregulated (Table V). As shown in Figures 10 and 6 upregulated genes (ACAA1, ACSL1, ACADM, $A C A D L, C P T 1 A$, and $C P T 1 B)$, which were related to fatty acid oxidation, were shared by these two signaling pathways. These findings suggest that these 6 upregulated genes may play important roles in activating these two signaling pathways and regulating IMF deposition in pigs.

\section{DISCUSSION}

In the modern pig breeding industry, IMF content has become an important determinant of meat quality for raisers and consumers. There was significant difference in IMF content between Chinese local pigs and famous commercial lean pigs. As a typical lean-type pig breed, the Large White 

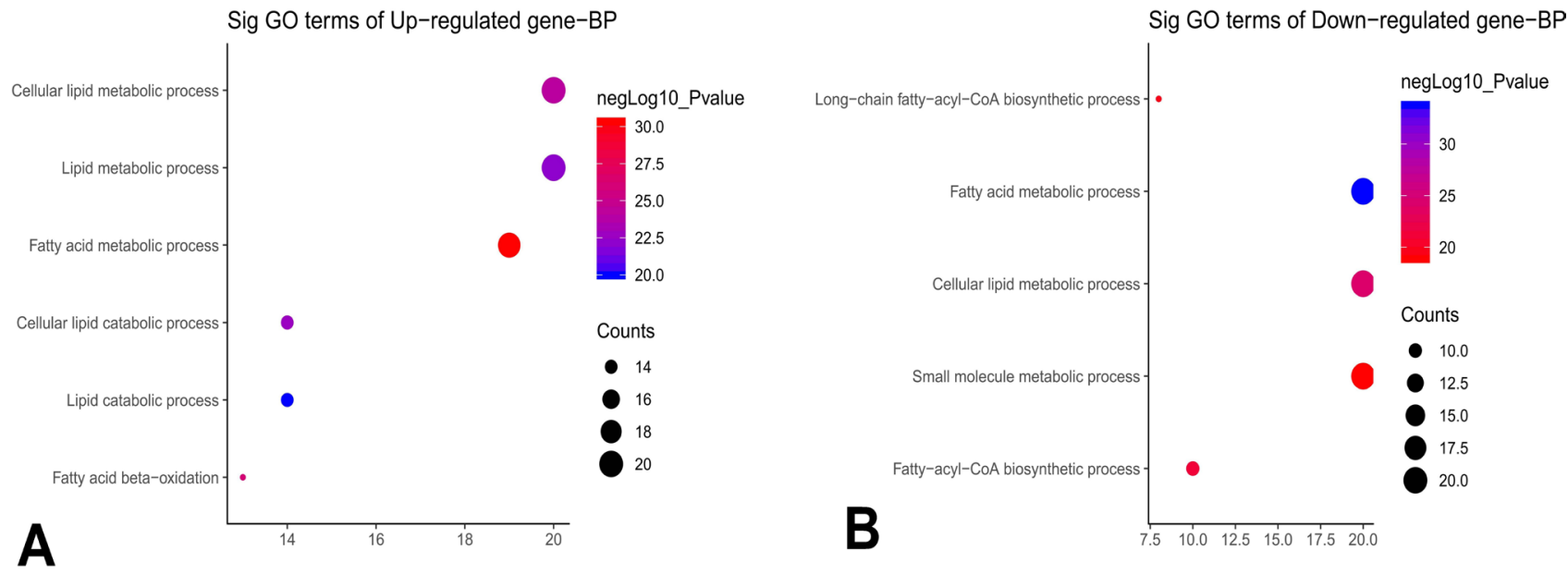

Fig. 9. GO Biological Process (BP) enrichment of upregulated (A) and downregulated (B) genes in the fatty acid metabolism signaling pathway.

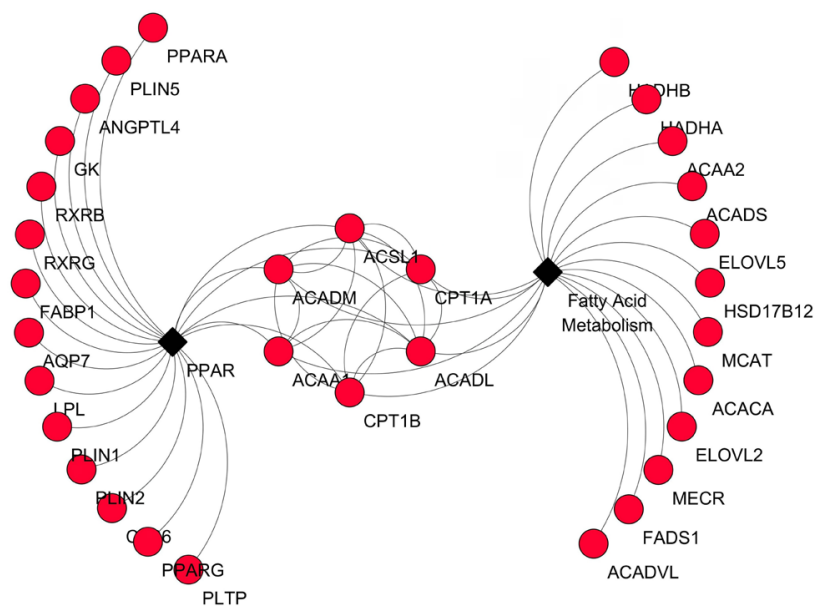

Fig. 10. The upregulated genes shared by the PPAR and fatty acid metabolism signaling pathways.

grows faster and has lower IMF content. By contrast, the Min pig is a well-known Chinese fat-type pig breed and characterized by high intramuscular fat (IMF) content, and in our results, we also found that the Min pig had higher IMF content than that in Large White pig (Fig. 1). Unfortunately, the differences in IMF content of these two pig breeds are not fully understood. The search for candidate genes and signaling pathways associated with IMF deposition is necessary. The IMF deposition is known to be regulated by multiple genes and signaling pathways. At present, many studies have focused on finding candidate genes and potential mechanisms associated with regulation of IMF deposition in pig, few studies focus on the correlation of signaling pathways with IMF content in different pig breeds. Therefore, in the present research, the expression levels of all genes in the PPAR and fatty acid metabolism signaling pathways were detected by a qRT-PCR array. Our research will help cultivate more valuable commodity pig breeds.

PPAR signaling pathway has long been considered important for fatty acid metabolism and meat quality in mammals (He et al., 2013; Wang et al., 2016), genes of which are involved in three biological processes: lipogenesis, fatty acid transport and fatty acid oxidation, that have been reported to associate with IMF deposition. The DEGs we obtained from our experiment are all involved in the three biological processes: (1) fatty acid transport (FAT/CD36, FABP1, FABP3, FABP5, ACSL1, ACSBG2, and LPL) (Bonen et al., 2004; Campbell et al., 2004; Jiang and Li, 2006; Luo et al., 2009; Ellis et al., 2010; Liu et al., 2011; Serao et al., 2011; Widmann et al., 2011; Jeong et al., 2015; Wang et al., 2017), (2) fatty acid oxidation (CPT1A, CPT1B, $A C A A 1, A C A D M$, and $A C A D L$ ) (Kim et al., 2000; Zha et al., 2005; Wu et al., 2013; Puig-Oliveras et al., 2014; Zhang et al., 2014; Chen et al., 2017; Qiu et al., 2017; Wang et al., 2017), (3) lipogenesis (SCD) (Wang et al., 2013, 2015; RosFreixedes et al., 2016). Compared with the Min pig group, four fatty acid transport-related genes (FAT/CD36, FABP1, $A C S L 1$, and $L P L)$ and five fatty acid oxidation-related genes (CPT1A, CPT1B, ACAA1, ACADM, and $A C A D L)$ were highly upregulated, and the lipogenesis-related gene $(S C D)$ was downregulated in the Large White pig group (Fig. 4, Table I), which indicated that the ability of transport fatty acids and fatty acid oxidation in Large White was stronger than Min, and the rate of fatty acid synthesis in Large White was weaker than Min. The dynamic balance between fatty acid synthesis and degradation affects the IMF content in pigs, the different ability of fatty acid oxidative degradation and synthesis could contribute to the difference in IMF 
content between Large White than Min pig breeds.

Table III. qRT-PCR array results for the fatty acid metabolism signaling pathway (Large White-Min).

\begin{tabular}{|c|c|c|c|}
\hline Gene symbol & Fold-change & P-value & Regulation \\
\hline$A C A D V L$ & 4.1670828 & $2.00 \mathrm{E}-08$ & Up \\
\hline FADS1 & 4.14549659 & $2.01 \mathrm{E}-07$ & Up \\
\hline CPT1B & 4.09616108 & 2.79E-06 & Up \\
\hline$A C A D L$ & 3.84362718 & $6.38 \mathrm{E}-09$ & Up \\
\hline$M E C R$ & 3.65267791 & $8.44 \mathrm{E}-08$ & Up \\
\hline CPT1A & 3.34806208 & $5.37 \mathrm{E}-10$ & Up \\
\hline ELOVL2 & 3.20952208 & 2.99E-09 & Up \\
\hline$A C A C A$ & 3.05264456 & $1.26 \mathrm{E}-03$ & Up \\
\hline$A C S L 1$ & 3.00794678 & $5.34 \mathrm{E}-09$ & Up \\
\hline$A C A D M$ & 2.96759173 & $2.26 \mathrm{E}-06$ & Up \\
\hline$M C A T$ & 2.75248718 & $4.25 \mathrm{E}-06$ & Up \\
\hline$A C A A 1$ & 2.56635317 & $1.60 \mathrm{E}-13$ & Up \\
\hline$H S D 17 B 12$ & 2.55652762 & $1.26 \mathrm{E}-10$ & Up \\
\hline ELOVL5 & 2.4520947 & $1.41 \mathrm{E}-03$ & Up \\
\hline$A C A D S$ & 2.36525946 & $2.93 \mathrm{E}-11$ & Up \\
\hline$A C A A 2$ & 2.08178922 & $1.38 \mathrm{E}-07$ & Up \\
\hline HADHA & 2.04896505 & $2.05 \mathrm{E}-08$ & Up \\
\hline$H A D H B$ & 2.03345962 & $1.52 \mathrm{E}-08$ & Up \\
\hline FADS2 & -2.1272039 & $1.00 \mathrm{E}-04$ & Down \\
\hline$S C D$ & -2.1705451 & $1.23 \mathrm{E}-04$ & Down \\
\hline$H A C D 3$ & -2.1842869 & $7.22 \mathrm{E}-07$ & Down \\
\hline$A C S B G 1$ & -2.2320913 & 7.14E-02 & Down \\
\hline HACD4 & -2.3350926 & $4.12 \mathrm{E}-07$ & Down \\
\hline ACSL6 & -2.4473721 & $1.98 \mathrm{E}-08$ & Down \\
\hline EHHADH & -2.5648137 & $1.28 \mathrm{E}-03$ & Down \\
\hline$A C S B G 2$ & -2.7882804 & 7.69E-04 & Down \\
\hline CPTIC & -2.7955525 & $8.71 \mathrm{E}-06$ & Down \\
\hline$A C A T 2$ & -2.9258849 & $6.10 \mathrm{E}-05$ & Down \\
\hline SCD5 & -2.9605646 & $6.16 \mathrm{E}-06$ & Down \\
\hline ELOVL6 & -3.1983219 & $2.50 \mathrm{E}-09$ & Down \\
\hline PECR & -6.4503496 & 7.49E-08 & Down \\
\hline
\end{tabular}

Table IV. The summary for the PPI network of DEGs in the fatty acid metabolism signaling pathway.

\begin{tabular}{|c|c|}
\hline Gene symbol & Degree \\
\hline ACSL1 & 18 \\
\hline$A C A D L$ & 17 \\
\hline$A C A D M$ & 17 \\
\hline ЕHHADH & 16 \\
\hline$A C A A 2$ & 16 \\
\hline$H A D H B$ & 16 \\
\hline CPT1A & 15 \\
\hline$A C A C A$ & 15 \\
\hline HADHA & 14 \\
\hline$A C S B G 2$ & 13 \\
\hline$C P T 1 B$ & 13 \\
\hline HSD17B12 & 13 \\
\hline$A C A D S$ & 13 \\
\hline$S C D$ & 12 \\
\hline ELOVL6 & 12 \\
\hline ACAT2 & 12 \\
\hline$A C A D V L$ & 12 \\
\hline ACSL6 & 11 \\
\hline CPT1C & 11 \\
\hline ELOVL5 & 11 \\
\hline$A C A A 1$ & 11 \\
\hline FADS1 & 10 \\
\hline FADS2 & 10 \\
\hline$A C S B G 1$ & 9 \\
\hline$M E C R$ & 8 \\
\hline ELOVL2 & 8 \\
\hline SCD5 & 7 \\
\hline PTPLAD2 & 5 \\
\hline PTPLAD1 & 5 \\
\hline PECR & 4 \\
\hline$M C A T$ & 2 \\
\hline
\end{tabular}

The top ten degree genes were shown in bold.

Moreover, as one of the key regulators in the PPAR signaling pathway, the peroxisome proliferator-activated receptor $\alpha$ gene (PPAR $\alpha)$ plays a critical role in fatty acid oxidation and IMF deposition in pigs and rats (He et al., 2013; Wang et al., 2016; Zhang et al., 2016). In addition, many studies have reported that PPAR $\alpha$ regulated lipid metabolism through targeting genes involved in fatty acid uptake $(F A B P 1, L P L)$, fatty acid transport $(F A T / C D 36$, $A C S L 1$, and $F A B P 1)$ and fatty acid oxidation (ACADS, 
ACADM, ACADL, ACADVL, CPT1A, CPT1B and ACAA1) (Rakhshandehroo et al., 2010; Gessner et al., 2015; Xu et al., 2015; Zhang et al., 2016). Consistent with these findings, PPAR $\alpha$ was highly expressed in the Large White pig group (Fig. 4, Table I), implying that PPAR $\alpha$ has a positive role in reducing the IMF content in pigs. Taken together, all these results above make it tempting to suggest that the activation of the PPAR signaling pathway may play positive role in reducing the IMF content in the LD muscle of Large White pigs.

Table V. The Venn diagram summaries for the PPAR and fatty acid metabolism signaling pathways.

The genes shared by the PPAR and fatty acid metabolism
signaling pathways
$C P T 1 A, A C S L 1, S C D 5, A C S L 6, A C S L 5, A C S L 4, A C S L 3$,
$C P T 1 C, C P T 1 B, F A D S 2, C P T 2, A C A D L$,
$A C O X 1, S C D, E H H A D H, A C S B G 1, A C A D M, A C O X 3, A C A A 1$,
$A C S B G 2$
The DEGs shared by the PPAR and fatty acid metabolism
signaling pathways
CPT1A, ACADL, ACSL1, SCD, ACSBG1, ACADM, ACAA1,
CPT1B, $A C S B G 2, S C D 5$

The shared upregulated genes were shown in bold.

At the same time, the fatty acid metabolism signaling pathway also plays an important role in regulating fatty acid metabolism and growth traits in pigs (Yang et al., 2012). The biological processes lipogenesis, fatty acid transport and fatty acid oxidation are also critical to this fatty acid metabolism-related signaling pathway, and many genes in this signaling pathway have been widely studied. In our results (Fig. 8, Table III), fatty acid transport-related gene (ACSL1) (Ellis et al., 2010; Widmann et al., 2011), the first step of mitochondrial fatty acid $\beta$-oxidationrelated genes ( $A C A D S, A C A D M, A C A D L$, and $A C A D V L$ ) (Puig-Oliveras et al., 2014; Chen et al., 2017; Wang et al., 2017), the last three steps of mitochondrial fatty acid $\beta$-oxidation-related genes ( $H A D H A$ and $H A D H B$ ) (Zha et al., 2005), the last step of the mitochondrial fatty acid $\beta$-oxidation-related gene (ACCA2) (Doi et al., 2003; Zha et al., 2005), the gene involved in peroxisomal fatty acid oxidation (ACAA1) (Wu et al., 2013) and the rate-limiting genes of mitochondrial fatty acid $\beta$-oxidation $(C P T 1 A$ and CPT1B) (Kim et al., 2000; Zhang et al., 2014; Qiu et al., 2017) were all highly expressed in the LD muscle of Large White pigs, and the fatty acid synthesis-related gene $(S C D)$ had a low expression level in the Large White group. These results indicated that the Large White pig has stronger ability of fatty acid oxidation, which might lead to fatty acid degradation and low IMF content in the LD muscle of Large White pig breeds. Finally, taking into account the results above, our results indicate that the activation of the fatty acid metabolism signaling pathway may reduce the IMF content in the LD muscle of Large White pigs.

Interestingly, among the upregulated genes in these two signaling pathways, six genes (ACAA1, ACSL1, $A C A D M, A C A D L, C P T 1 A$, and $C P T 1 B$ ) (Fig. 10) were shared by them. Notably, acyl-CoA synthetase-1 (ACSL1), one member of the long chain acyl-CoA synthetase family (ACSLs), is essential for fatty acid uptake, oxidation and degradation. ACSL1 is required for the initial step of fatty acid oxidation and specifically directs fatty acids towards mitochondrial $\beta$-oxidation (Ellis et al., 2010; Widmann et al., 2011). Carnitine palmitoyltransferase-1 (CPT1) has been regarded as a rate-limiting enzyme of mitochondrial fatty acid $\beta$-oxidation and is closely related to fat deposition. In addition, a high expression level of $C P T 1$ could promote fatty acid decomposition and decrease fat deposition. Additionally, CPTIA and CPTIB, two common isoforms of $C P T 1$, play prominent roles in fatty acid oxidation and lipid accumulation in human, chicken and pigs (Kim et al., 2000; Zhang et al., 2014; Qiu et al., 2017), the decrease in fat deposition are associated with high expression levels of these two genes. Acyl-CoA dehydrogenase medium chainand long chain ( $A C A D M$ and $A C A D L$ ) encode the acylCoA dehydrogenases ( $M C A D$ and $\angle C A D)$ and catalyze the first step of mitochondrial fatty acid $\beta$-oxidation (Hashimoto et al., 1999; Wang et al., 2017). Several researchers have reported that these two genes are closely related to IMF deposition in pigs (Puig-Oliveras et al., 2014; Chen et al., 2017; Wang et al., 2017). Acetyl-CoA acyltransferase (ACAA1), also called peroxisomal 3-ketoacyl-CoA thiolase, is encoded by the $A C A A 1$ gene and involved in peroxisomal fatty acid oxidation (Zha et al., 2005). In addition, this gene is also related to the IMF content trait in the LD of pigs (Wu et al., 2013). In this study, these six genes were all upregulated in the LD muscle of Large White pigs, which appears to show that these six genes are important for the activation of the PPAR and fatty acid metabolism signaling pathways, and they might be potential candidate genes to identify mechanisms that regulate IMF deposition in pigs.

\section{CONCLUSIONS}

In conclusion, our study reports the expression profiles of the PPAR and fatty acid metabolism signaling pathwayrelated genes in two pig breeds. Although the abundance of mRNA has been determined in our study, it is necessary to investigation DEGs with multi-omics analysis in the subsequent studies. Our results suggest that the activation of these two signaling pathways may play a positive role 
in reducing IMF content in pigs. These findings may also provide new insights into the key signaling pathways involved in fat deposition in pigs.

\section{ACKNOWLEDGMENTS}

This work was supported by Special Funds for Cultivation and Breeding of New Transgenic Organisms (No. 2016ZX08006001 \& 2016ZX08006003), the Program for JLU Science and Technology Innovative Research Team (2017TD-28), and the Fundamental Research Funds for the Central Universities. We thank Dr. Wentao Wang and Dr. Xinmiao He (Heilongjiang Academy of Agricultural Sciences) for their help in sample collection. We thank American Journal Experts (https://www.aje.com/) for its linguistic assistance during the preparation of this manuscript.

\section{Statement of conflicts of interest}

The authors declare that there are no conflicts of interest regarding the publication of this paper.

\section{Supplementary materials}

There are two supplementary tables in MS Word associated with this article. Access these online at: https:// dx.doi.org/10.17582/journal.pjz/20190407110454

\section{REFERENCES}

Bonen, A., Campbell, S.E., Benton, C.R., Chabowski, A., Coort, S.L.M., Han, X.X., Koonen, D.P.Y., Glatz, J.F.C. and Luiken, J.J.F.P., 2004. Regulation of fatty acid transport by fatty acid translocase/cd36. Proc. Nutri. Soc., 63: 245-249. https://doi.org/10.1079/ PNS2004331

Campbell, S.E., Tandon, N.N., Woldegiorgis, G., Luiken, J.J.F.P., Glatz, J.F.C. and Bonen, A., 2004. A novel function for fatty acid translocase (fat)/cd36involvement in long chain fatty acid transfer into the mitochondria. J. biol. Chem., 279: 36235-36241. https://doi.org/10.1074/jbc.M400566200

Casellas, J., Vidal, O., Pena, R.N., Gallardo, D., Manunza, A., Quintanilla, R. and Amills, M., 2013. Genetics of serum and muscle lipids in pigs. Anim. Genet., 44: 609-619. https://doi.org/10.1111/age.12049

Chen, W., Fang, G.F., Wang, S.D., Wang, H. and Zeng, Y.Q., 2017. Longissimus lumborum muscle transcriptome analysis of laiwu and yorkshire pigs differing in intramuscular fat content. Genes Genom, 39: 759-766. https://doi.org/10.1007/s13258-017-
0540-9

Cui, J., Chen, W., Liu, J., Xu, T. and Zeng, Y., 2016. Study on quantitative expression of ppargamma and adrp in muscle and its association with intramuscular fat deposition of pig. Springer Plus, 5: 1501. Available from http://www.ncbi.nlm.nih.gov/ pubmed/27652074. https://doi.org/10.1186/s40064016-3187-0

Dai, F.W., Feng, D.Y., Cao, Q.Y., Ye, H., Zhang, C.M., Xia, W.G. and Zuo, J.J., 2009. Developmental differences in carcass, meat quality and muscle fibre characteristics between the landrace and a chinese native pig. S. Afr. J. Anim. Sci., 39: 267-273. https:// doi.org/10.4314/sajas.v39i4.51126

Doi, M., Kondo, Y. and Tsutsumi, K., 2003. Lipoprotein lipase activator no-1886 (ibrolipim) accelerates the mrna expression of fatty acid oxidation-related enzymes in rat liver. Metabolism, 52: 1547-1550. https://doi.org/10.1016/j.metabol.2003.07.007

Ellis, J.M., Li, L.O., Wu, P.C., Koves, T.R., Ilkayeva, O., Stevens, R.D., Watkins, S.M., Muoio, D.M. and Coleman, R.A., 2010. Adipose acyl-coa synthetase-1 directs fatty acids toward beta-oxidation and is required for cold thermogenesis. Cell Metab., 12: 53-64. https://doi.org/10.1016/j.cmet.2010.05.012

Font-i-Furnols, M., Tous, N., Esteve-Garcia, E. and Gispert, M., 2012. Do all the consumers accept marbling in the same way? The relationship between eating and visual acceptability of pork with different intramuscular fat content. Meat Sci., 91: 448-453. https://doi.org/10.1016/j.meatsci.2012.02.030

Gao, Y., Zhang, Y.H., Jiang, H., Xiao, S.Q., Wang, S., Ma, Q., Sun, G.J., Li, F.J., Deng, Q., Dai, L.S., Zhao, Z.H., Cui, X.S., Zhang, S.M., Liu, D.F. and Zhang, J.B., 2011. Detection of differentially expressed genes in the longissimus dorsi of northeastern indigenous and large white pigs. Genet. Mol. Res., 10: 779-791. https://doi.org/10.4238/vol10-2gmr1170

Gessner, D.K., Grone, B., Rosenbaum, S., Most, E., Hillen, S., Becker, S., Erhardt, G., Reiner, G., Ringseis, R. and Eder, K., 2015. Effect of a negative energy balance induced by feed restriction in lactating sows on hepatic lipid metabolism, milk production and development of litters. Arch. Anim. Nutri., 69: 399-410. https://doi.org/10.1080/174503 9X.2015.1075669

Hamill, R.M., Aslan, O., Mullen, A.M., O’Doherty, J.V., McBryan, J., Morris, D.G. and Sweeney, T., 2013. Transcriptome analysis of porcine $\mathrm{m}$. Semimembranosus divergent in intramuscular fat as a consequence of dietary protein restriction. $B M C$ Genom., 14. https://doi.org/10.1186/1471-2164-14- 
453

Hashimoto, T., Fujita, T., Usuda, N., Cook, W., Qi, C., Peters, J.M., Gonzalez, F.J., Yeldandi, A.V., Rao, M.S. and Reddy, J.K., 1999. Peroxisomal and mitochondrial fatty acid beta-oxidation in mice nullizygous for both peroxisome proliferatoractivated receptor alpha and peroxisomal fatty acyl-coa oxidase - genotype correlation with fatty liver phenotype. J. biol. Chem., 274: 19228-19236. https://doi.org/10.1074/jbc.274.27.19228

He, K., Wang, Q.S., Wang, Z. and Pan, Y.C., 2013. Association study between gene polymorphisms in ppar signaling pathway and porcine meat quality traits. Mammal. Genome, 24: 322-331. https://doi. org/10.1007/s00335-013-9460-4

Jeong, H., Song, K.D., Seo, M., Caetano-Anolles, K., Kim, J., Kwak, W., Oh, J.D., Kim, E., Jeong, D.K., Cho, S., Kim, H. and Lee, H.K., 2015. Exploring evidence of positive selection reveals genetic basis of meat quality traits in berkshire pigs through whole genome sequencing. BMC Genet., 16. https:// doi.org/10.1186/s12863-015-0265-1

Jiang, Y.Z. and Li, X.W., 2006. Sequence characterization, tissue-specific expression and polymorphism of the porcine intestinal-type fatty acid binding protein gene. Can. J. Anim. Sci., 86: 561-567. https://doi. org/10.4141/A05-076

Kim, J.Y., Hickner, R.C., Cortright, R.L., Dohm, G.L. and Houmard, J.A., 2000. Lipid oxidation is reduced in obese human skeletal muscle. Am. J. Physiol-Endocrinol., 279: E1039-E1044. https://doi. org/10.1152/ajpendo.2000.279.5.E1039

Li, B., Weng, Q., Dong, C., Zhang, Z., Li, R., Liu, J., Jiang, A., Li, Q., Jia, C., Wu, W. and Liu, H., 2018. A key gene, plin1, can affect porcine intramuscular fat content based on transcriptome analysis. Genes, 9. Available from http://www.ncbi.nlm.nih. gov/pubmed/29617344. https://doi.org/10.3390/ genes 9040194

Li, X.J., Zhou, J., Liu, L.Q., Qian, K. and Wang, C.L., 2016. Identification of genes in longissimus dorsi muscle differentially expressed between wannanhua and yorkshire pigs using rna-sequencing. Anim. Genet., 47: 324-333. https://doi.org/10.1111/ age. 12421

Lim, K.S., Lee, K.T., Park, J.E., Chung, W.H., Jang, G.W., Choi, B.H., Hong, K.C. and Kim, T.H., 2017. Identification of differentially expressed genes in longissimus muscle of pigs with high and low intramuscular fat content using rna sequencing. Anim. Genet., 48: 166-174. https://doi.org/10.1111/ age. 12518
Liu, Y., Wang, Z.B., Yin, W.D., Li, Q.K., Cai, M.B., Yu, J., Li, H.G., Zhang, C. and Zu, X.H., 2011. Preventive effect of ibrolipim on suppressing lipid accumulation and increasing lipoprotein lipase in the kidneys of diet-induced diabetic minipigs. Lipids Hlth. Dis., 10. https://doi.org/10.1186/1476-511X-10-117

Luo, H.F., Wei, H.K., Huang, F.R., Zhou, Z., Jiang, S.W. and Peng, J., 2009. The effect of linseed on intramuscular fat content and adipogenesis related genes in skeletal muscle of pigs. Lipids, 44: 9991010. https://doi.org/10.1007/s11745-009-3346-y

Madeira, M.S., Costa, P., Alfaia, C.M., Lopes, P.A., Bessa, R.J.B., Lemos, J.P.C. and Prates, J.A.M., 2013. The increased intramuscular fat promoted by dietary lysine restriction in lean but not in fatty pig genotypes improves pork sensory attributes. $J$. Anim. Sci., 91: 3177-3187. https://doi.org/10.2527/ jas.2012-5424

Morales-Prieto, N., Pueyo, C. and Abril, N., 2017. Validation of commercial real-time pcr-arrays for environmental risk assessment: Application to the study of p,p'-dde toxicity in mus spretus mice liver. Environ. Pollut., 230: 178-188. https://doi. org/10.1016/j.envpol.2017.06.031

Puig-Oliveras, A., Ramayo-Caldas, Y., Corominas, J., Estelle, J., Perez-Montarelo, D., Hudson, N.J., Casellas, J., Folch, J.M. and Ballester, M., 2014. Differences in muscle transcriptome among pigs phenotypically extreme for fatty acid composition. PLoS One, 9: e99720. https://doi.org/10.1371/ journal.pone.0099720

Qiu, F.F., Xie, L., Ma, J.E., Luo, W., Zhang, L., Chao, Z., Chen, S.H., Nie, Q.H., Lin, Z.M. and Zhang, X.Q., 2017. Lower expression of slc27a1 enhances intramuscular fat deposition in chicken via downregulated fatty acid oxidation mediated by cpt1a. Front. Physiol., 8: 449. https://doi.org/10.3389/ fphys.2017.00449

Rakhshandehroo, M., Knoch, B., Muller, M. and Kersten, S., 2010. Peroxisome proliferator-activated receptor alpha target genes. PPAR Res., 2010: 612089 https:// doi.org/10.1155/2010/612089

Ros-Freixedes, R., Gol, S., Pena, R.N., Tor, M., IbanezEscriche, N., Dekkers, J.C.M. and Estany, J., 2016. Genome-wide association study singles out scd and lepr as the two main loci influencing intramuscular fat content and fatty acid composition in duroc pigs. PLoS One, 11: e0152496 https://doi.org/10.1371/ journal.pone.0152496

Serao, N.V.L., Veroneze, R., Ribeiro, A.M.F., Verardo, L.L., Neto, J.B., Gasparino, E., Campos, C.F., Lopes, P.S. and Guimaraes, S.E.F., 2011. Candidate 
gene expression and intramuscular fat content in pigs. J. Anim. Breed Genet., 128: 28-34. https://doi. org/10.1111/j.1439-0388.2010.00887.x

Shannon, P., Markiel, A., Ozier, O., Baliga, N.S., Wang, J.T., Ramage, D., Amin, N., Schwikowski, B. and Ideker, T., 2003. Cytoscape: A software environment for integrated models of biomolecular interaction networks. Genome Res., 13: 2498-2504. https://doi. org/10.1101/gr.1239303

Supakankul, P. and Mekchay, S., 2016. Association of nlk polymorphisms with intramuscular fat content and fatty acid composition traits in pigs. Meat Sci., 118: 61-65. https://doi.org/10.1016/j. meatsci.2016.03.025

Szklarczyk, D., Franceschini, A., Wyder, S., Forslund, K., Heller, D., Huerta-Cepas, J., Simonovic, M., Roth, A., Santos, A., Tsafou, K.P., Kuhn, M., Bork, P., Jensen, L.J. and von Mering, C., 2015. String v10: Protein-protein interaction networks, integrated over the tree of life. Nucl. Acids Res., 43: D447-D452. https://doi.org/10.1093/nar/gku1003

Tao, Y.F., Wu, D., Pang, L., Zhao, W.L., Lu, J., Wang, N., Wang, J., Feng, X., Li, Y.H., Ni, J. and Pan, J., 2012. Analyzing the gene expression profile of pediatric acute myeloid leukemia with real-time pcr arrays. Cancer Cell Int., 12: 40. https://doi. org/10.1186/1475-2867-12-40

Wang, L.Y., Li, X.X., Ma, J., Zhang, Y.W. and Zhang, H., 2017. Integrating genome and transcriptome profiling for elucidating the mechanism of muscle growth and lipid deposition in pekin ducks. Scient. Rep., 7: 3837. https://doi.org/10.1038/s41598-01704178-7

Wang, W., Xue, W., Xu, X., Jin, B. and Zhang, X., 2016. Correlations of genes expression in ppar signalling pathway with porcine meat quality traits. Czech. J. Anim. Sci., 61: 333-339.

Wang, W., Xue, W.D., Jin, B.Q., Zhang, X.X., Ma, F. and $\mathrm{Xu}, \mathrm{X} . \mathrm{F} .$, 2013. Candidate gene expression affects intramuscular fat content and fatty acid composition in pigs. J. appl. Genet., 54: 113-118. https://doi. org/10.1007/s13353-012-0131-z

Wang, X.W., Ding, R.R., Quan, J.P., Yang, L.X., Yang, M., Zheng, E.Q., Liu, D.W., Cai, G.Y., Wu, Z.F. and Yang, J., 2017. Genome-wide association analysis reveals genetic loci and candidate genes associated with intramuscular fat in duroc pigs. Front. agric. Sci. Eng., 4: 335-341. https://doi.org/10.15302/JFASE-2017152

Wang, Z.X., Li, Q.G., Chamba, Y., Zhang, B., Shang, P., Zhang, H. and Wu, C.X., 2015. Identification of genes related to growth and lipid deposition from transcriptome profiles of pig muscle tissue. PLoS One, 10: e0141138. https://doi.org/10.1371/journal. pone. 0141138

Wang, Z.X., Shang, P., Li, Q.G., Wang, L.Y., Chamba, Y.Z., Zhang, B., Zhang, H. and Wu, C.X., 2017. Itraq-based proteomic analysis reveals key proteins affecting muscle growth and lipid deposition in pigs. Scient. Rep., 7: 46717. https://doi.org/10.1038/ srep46717

Widmann, P., Nuernberg, K., Kuehn, C. and Weikard, R., 2011. Association of an acsl1 gene variant with polyunsaturated fatty acids in bovine skeletal muscle. BMC Genet., 12: 96. https://doi.org/10.1186/14712156-12-96

Wu, T., Zhang, Z.H., Yuan, Z.Q., Lo, L.J., Chen, J., Wang, Y.Z. and Peng, J.R., 2013. Distinctive genes determine different intramuscular fat and muscle fiber ratios of the longissimus dorsi muscles in jinhua and landrace pigs. PLoS One, 8: e53181. https://doi. org/10.1371/journal.pone.0053181

$\mathrm{Xu}$, L., Huang, D.P., Hu, Q.L., Wu, J., Wang, Y.Z. and Feng, J., 2015. Betaine alleviates hepatic lipid accumulation via enhancing hepatic lipid export and fatty acid oxidation in rats fed with a high-fat diet (vol 113, pg 1835, 2015). Brit. J. Nutr., 114: 995996. https://doi.org/10.1017/S0007114515002901

Yang, F., Wang, Q.P., Wang, M.H., He, K. and Pan, Y.C., 2012. Associations between gene polymorphisms in two crucial metabolic pathways and growth traits in pigs. Chinese Sci. Bull., 57: 2733-2740. https://doi. org/10.1007/s11434-012-5328-3

Zha, S., Ferdinandusse, S., Hicks, J.L., Denis, S., Dunn, T.A., Wanders, R.J., Luo, J., De Marzo, A.M. and Isaacs, W.B., 2005. Peroxisomal branched chain fatty acid beta-oxidation pathway is upregulated in prostate cancer. Prostate, 63: 316-323. https://doi. org/10.1002/pros.20177

Zhang, C., Luo, J.Q., Zheng, P., Yu, B., Huang, Z.Q., Mao, X.B., He, J., Yu, J., Chen, J.L. and Chen, D.W., 2015. Differential expression of lipid metabolismrelated genes and myosin heavy chain isoform genes in pig muscle tissue leading to different meat quality. Animal, 9: 1073-1080. https://doi.org/10.1017/ S1751731115000324

Zhang, Y., Guo, H.L., Hassan, H.M., Ding, P.P., Su, Y.J., Song, Y.M., Wang, T., Sun, L.X., Zhang, L.Y. and Jiang, Z.Z., 2016. Pyrazinamide induced hepatic injury in rats through inhibiting the ppar alpha pathway. J. appl. Toxicol., 36: 1579-1590. https:// doi.org/10.1002/jat.3319

Zhang, Y.F., Yuan, Z.Q., Song, D.G., Zhou, X.H. and Wang, Y.Z., 2014. Effects of cannabinoid receptor 
1 (brain) on lipid accumulation by transcriptional control of cptla and cptlb. Anim. Genet., 45: 38-47. https://doi.org/10.1111/age.12078

Zhao, S.M., Ren, L.J., Chen, L., Zhang, X., Cheng, M.L., Li, W.Z., Zhang, Y.Y. and Gao, S.Z., 2009.
Differential expression of lipid metabolism related genes in porcine muscle tissue leading to different intramuscular fat deposition. Lipids, 44: 1029-1037. https://doi.org/10.1007/s11745-009-3356-9 